\title{
Analysis of the Correlation between Cross-Border E-Commerce and Economic Growth Based on Hierarchical Multilevel Gray Evaluation Model
}

\author{
Nie Chen \\ Department of Electronic Commerce, Zhejiang Business Technology Institute, Ningbo 315012, China \\ Correspondence should be addressed to Nie Chen; 20820048@zbti.edu.cn
}

Received 16 December 2021; Accepted 15 January 2022; Published 7 February 2022

Academic Editor: Miaochao Chen

Copyright (c) 2022 Nie Chen. This is an open access article distributed under the Creative Commons Attribution License, which permits unrestricted use, distribution, and reproduction in any medium, provided the original work is properly cited.

\begin{abstract}
Cross-border e-commerce is a new form of global trade development under the background of "Internet+," and it is also a new engine driving economic development. Cross-border e-commerce is growing rapidly and has broad development prospects. As a pioneering pilot zone for comprehensive cross-border e-commerce, it has played a leading role in the development of the country's cross-border e-commerce industry. This paper takes China's 35 cross-border e-commerce comprehensive pilot areas as the research object, selects the annual data of 31 provinces across the country, and conducts an empirical research based on the gray-related Internet development level and economic growth. It analyzes the influencing factors of cross-border ecommerce development, constructs a cross-border e-commerce development influencing factor model, and applies gray theory to conduct an empirical analysis of the correlation between cross-border e-commerce development influencing factors and cross-border e-commerce. The research results show that foreign direct investment has the greatest correlation with the number of websites and webpages; the number of patent applications has the greatest correlation with the number of domains and websites; the total fixed assets have the greatest correlation with the number of Internet users and the number of mobile phones at the end of the year; the total amount of foreign investment enterprises in and out. It has the greatest correlation with the number of URLs and Webpages; GDP has the greatest correlation with the number of Internet users and the number of mobile phones at the end of the year. The Internet infrastructure and popularity have a close relationship with economic growth, and the relationship between foreign investment and patent applications and the level of Internet development is more significant.
\end{abstract}

\section{Introduction}

In the recent years, the inherent relationship between the Internet and economic growth has also become one of the academic research hotspots. Compared with traditional trade distributors, the richness and optional categories have increased significantly, and the product update speed has been faster. Thanks to the aid of cross-border e-commerce platforms, more high-quality brands can be sold globally, forming new profit growth points and lowering trade barriers. This is undoubtedly important for the internationalization of brands, the sustainable development of enterprises, and the integration of industries into the global value chain $[1-6]$.
Cross-border e-commerce is a new model of "Internet" + "manufacturing" + "brand" + "digitalization" + "trade," bringing new opportunities to manufacturing companies. It allows manufacturing companies to directly face foreign retailers and consumers. It has the characteristics of diversification, small batches, and less capital. It avoids the problems of large scale of traditional export trade, long transaction cycles, large capital, and information asymmetry. Cross-border e-commerce allows manufacturing companies with mature processing technology to go from behind the scenes to the world stage. Driven by information technology, it enables companies to overcome geographic and organizational boundaries and become more open, easier to collaborate, and more convenient to develop 
networks. Innovation, through the development of data technology, accumulation of data resources, application of data analysis, mining cross-cultural value, to meet the individual needs of consumers, with an international perspective, build a brand international operation mechanism on an international scale, and integrate domestic and foreign parties resources, promote multiparty collaboration to create brand value. Therefore, it is necessary to in-depth research, quantitatively analyze the correlation between factors, clarify the driving force and bottleneck of cross-border e-commerce development, and propose effective development countermeasures [7-9]. The e-commerce model of export activities mainly includes product selection, cross-border payment, settlement, logistics, and data transmission. The cross-border e-commerce ecosystem is composed of multiple modules such as buyers and sellers, public service agencies, professional service agencies, and the government [10-15]. It also can be shown as Figure 1.

Informatization is produced on the basis of advanced technologies such as computer science technology, communication engineering technology, and bioengineering technology, and represents the most advanced productivity in today's society. Informatization is an important support for promoting economic development, and it has a huge boosting effect on the economic development of a region. Informatization can promote the overall progress of the regional economy. Informatization can speed up the accumulation of knowledge in the region and create room for innovation in economic development [16-19].

China has a large land and a large population, and is affected by resources and national development policies, and its economic regional characteristics are relatively obvious. In recent years, the central government has also paid special attention to the construction of informatization, so many domestic experts and scholars have conducted in-depth discussions and research on this. Teng Li made a quantitative estimation and comprehensive evaluation of the informatization level of various provinces in China. Through data analysis, Meng Yuan concluded that the deepening of informatization has had a positive impact on economic growth. Gaoxincai analyzed the contribution rate of information elements and found that there is a significant positive correlation between the level of regional informatization and the level of economic development. Meilin used the gray correlation method and linear regression model to analyze the regional economic growth level of a region to a large extent determined by the level of informatization construction. Li Ling used the unary linear regression model to conclude that the level of informatization development plays an indelible role in promoting the regional economy. It can be seen that domestic scholars pay more attention to the influence of informatization on economic growth and affirm the important role of informatization in economic and social development [20-25].

Zhang Yue et al. established an evaluation model of the influence of the Internet development level on economic development by collecting relevant data on the economic and Internet development level of various regions. Tang Lingchao and others combined with time series data on economic growth, conducted an empirical analysis of the relationship between Internet development and GDP. More scholars pay attention to the macro analysis of Internet development and economic growth, while there is less research on the relationship between the two specific indicators. This paper uses the gray correlation model to quantitatively study the degree of correlation between the Internet development level and economic growth indicators, and calculate and analyze the degree of correlation between the indicators.

In 1982, Professor Deng Julong founded the Gray Theory, a new type of decision-making discipline and divided the system into three categories: white, black, and gray. The white system represents a system with completely transparent information, the black system is a system with completely unknown information, and the gray system is in the middle zone. Gray system theory is precisely through detailed analysis and in-depth mining of "known information" to predict and estimate "unknown information." It uses a small sample of "limited" and "poor information" to eliminate uncertainty.

On the contrary, the smaller the degree of relevance. The gray correlation degree is essentially a quantitative analysis method to describe and compare the dynamic development of the system [26-29]. The neural networks are shown in Figure 2. Cross-border e-commerce is achieved by buyers and sellers located in different zones, through the Internet information platform to achieve the information exchange and transaction of various goods or services, and through the provision of offline logistics services.

\section{Gray Relational Model}

It is a multi-index to examine the differences and relevance between the various elements of the system. We compare the sequence with the reference. When the sequence curves are similar, the two are considered to have a higher degree of correlation; otherwise, they are considered to have a lower degree of correlation, thus giving the strength and ranking of the relationship between the factors. Compared with other methods, the gray correlation analysis method requires less data volume, less sample size, and less calculation. The relative optimal value of each indicator can be used as a reference sequence to form the final comprehensive evaluation level. It can provide a basis for the determination without having to have high requirements on a large amount of practical data, which can better solve the problem that the flexible public transportation system as a new auxiliary public system does not have enough experience data to support its model parameters. In addition, the flexible public transportation system evaluation system is a comprehensive evaluation system based on passengers, bus companies, and the government. There are many factors involved, the indicators are more complex, some indicators are related and repetitive, and the information is relatively incomplete. The difference information principle of the gray system and the nonuniqueness principle of the solution can solve this problem very well. In summary, it is believed that it is more suitable for the comprehensive evaluation of flexible public 
transportation systems. However, the gray correlation analysis method treats all indicators as equal to the influencing factors of the overall target and does not consider the impact of indicator weights. The evaluation value has a low credibility. Scientific methods should be used to determine the indicator weights and associate them with the degree of relevance. The combination of coefficients increases the scientificity and validity of the evaluation results. The initial value processing of the absolute correlation degree adopts the initial point zeroing method, which mainly considers the relationship of the system development increment. Owing to the different measurement units of each factor, the greater the difference between the factors, the greater the impact on the accuracy of the result. The relative degree of relevance uses relative quantity for initial value processing, so the analysis result has nothing to do with the observed value of each factor. The comprehensive correlation degree also considers the relationship between increment and speed, which makes up for the shortcomings of the two to a certain extent.

Common weight determination methods include expert scoring method, equal-weight method, statistical test method, entropy method, and so on. The equal-weight method cannot well reflect the difference in the degree of influence of different indicators, and it is not conducive to the choice of the plan when the comprehensive evaluation value is not much different; the expert scoring method and the statistical test method are highly subjective and inapplicable. When there are many dry indicators, row and normalization method, column and inversion method, and so on, refer to the use of part of the data of the judgment matrix, and the result is not highly reliable; minimum deviation method, logarithmic regression method, and so on, use the same indicator with different schemes. It is believed that indicators with a greater degree of change convey more information and should have a higher weight. However, it is not applicable to the comprehensive-level evaluation of a single scheme of a flexible public transportation system. In this paper, the analytic hierarchy process is used to determine the weights of the various indicators of the system. It mathematicizes and organizes people's complex system thinking processes and integrates various factors of complex problems into orderly connected songs help to maintain the consistency of decisionmakers' thinking, apply to various types of complex comprehensive evaluation systems, can effectively integrate qualitative analysis and quantitative analysis, and have interchangeability and compatibility. Superior properties such as sex and symmetry are currently a common method for determining the weight of indicators.

2.1. Gray Absolute Relevance. It mainly reflects the relationship between the absolute increment of the two-factor data series, and the model is introduced as follows: Suppose the following sequence exists:

$x_{i}(k)=\left[x_{i}(1), x_{i}(2), \ldots, x_{i}(n)\right], \quad(i=0,1,2, \ldots, m)$.

The broken line is

$$
x_{i}^{0}=\left[x_{i}(1)-x_{i}(1), x_{i}(2)-x_{i}(1), \ldots, x_{i}(n)-x_{i}(1)\right] .
$$

Let

$$
S_{i}=\int_{1}^{n} x_{i}^{0} \mathrm{~d} t
$$

Then,

$$
\left|S_{i}-S_{0}\right|=\left|\int_{1}^{n}\left(x_{i}^{0}-x_{0}^{0}\right) \mathrm{d} t\right| .
$$

So the absolute degree of gray correlation is

$$
\xi_{0 i}=\frac{1+\left|s_{0}\right|+\left|s_{i}\right|}{1+\left|s_{0}\right|+\left|s_{i}\right|+\left|s_{i}-s_{0}\right|} .
$$

The size of the area between the two broken lines represented by the two-factor data series is the geometric meaning represented by the gray absolute correlation degree. Therefore, the larger the $\zeta_{0 i}$, the higher the similarity of the two-factor data sequence.

2.2. Gray Relative Degree of Relevance. The gray relative correlation degree mainly reflects the relationship between the growth rates of the two sequences. If the sequence is transformed into another kind of broken line, record the broken line:

$$
x_{i}^{1}=\left[\frac{x_{i}(1)}{x_{i}(1)}, \frac{x_{i}(2)}{x_{i}(1)}, \ldots, \frac{x_{i}(n)}{x_{i}(1)}\right] .
$$

Let

$$
S_{i}=\int_{1}^{n} x_{i}^{1} \mathrm{~d} t
$$

Then,

$$
\left|S_{i}-S_{0}\right|=\left|\int_{1}^{n}\left(x_{i}^{1}-x_{0}^{1}\right) \mathrm{d} t\right| .
$$

So the absolute degree of gray correlation is

$$
\omega_{0 i}=\frac{1+\left|s_{0}\right|+\left|s_{i}\right|}{1+\left|s_{0}\right|+\left|s_{i}\right|+\left|s_{i}-s_{0}\right|} .
$$

The larger the $\omega_{0 i}$ is, the closer the change rate.

2.3. Gray Comprehensive Relevance. Grey system theory includes gray system analysis, gray system prediction, and gray system decision-making, all of which are based on gray relational analysis. In order to more comprehensively reflect the closeness of the relationship between the two-factor data series, the average of the gray absolute correlation degree and the gray relative correlation degree is taken. The calculation of the average value mainly involves the value of the weight $\gamma$, which is between 0 and 1 . If the research is more concerned about the relationship between the rate changes of the twofactor data sequence, the value of $\gamma$ should be smaller; if the research is more concerned about the relationship between the incremental changes of the two-factor data sequence, the 
value of $\gamma$ can be larger. In this study, the value of $\gamma$ is 0.5 . Then

$$
\theta=\gamma \xi_{0 i}+(1-\gamma) \omega_{0 i} .
$$

The larger the $\theta$, the stronger the comprehensive correlation between the two sequences.

The gray relational analysis method has been widely used in solving the relationship between multiple factors. Its main steps are as follows:

(1) Dimensionless processing of indicators. Use the range standardization method to nondimensionally process the data:

$$
X_{i j}^{\prime}=\frac{\left(X_{i j}-\min _{i} X_{i j}\right)}{\max _{i} X_{i j}-\min _{i} X_{i j}} .
$$

(2) Generate the corresponding difference sequence. Calculate the absolute difference between the standardized reference data and the comparison data:

$$
\left|X_{i j}^{\prime}-Y_{i j}^{\prime}\right|
$$

Calculate the correlation coefficient and degree of correlation. Make the following transformations to the data in the corresponding difference sequence:

$$
\lambda_{i j}=\frac{\Delta(\min )+\rho \Delta(\max )}{\left|X_{i j}^{\prime}-Y_{i j}^{\prime}\right|+\rho \Delta(\max )} .
$$

$\lambda_{i j}$ represents the correlation coefficient and $\rho$ is the standardized coefficient value. The degree of correlation is as follows:

$$
\eta_{i j}=\frac{1}{n} \sum_{i=1}^{n} \lambda_{i j}
$$

According to the closeness of the relationship between the main behavior factors and related behavior factors in the gray system, determine the main and secondary factors that affect the development of the gray system. The selection of the Internet development level and economic growth indicators must not only reflect the application level of Internet development but also be able to measure the accuracy and comprehensiveness of economic growth. Existing literature often uses indicators such as the number of domain names, the number of Webpages, the number of websites, and the number of Internet users when selecting or constructing indicators of the Internet development level. This study uses the number of domain names, webpages, websites, Internet users, Internet penetration rate, mobile phone penetration rate, telephone penetration rate, and year-end number of mobile phones as the Internet development indicators. For the selection of economic growth indicators, most relevant studies use per capita GDP or the national GDP level, and a small number of GDP is deflated index processing to adjust the nominal value to the actual value. In order to more fully reflect the economic growth level of each

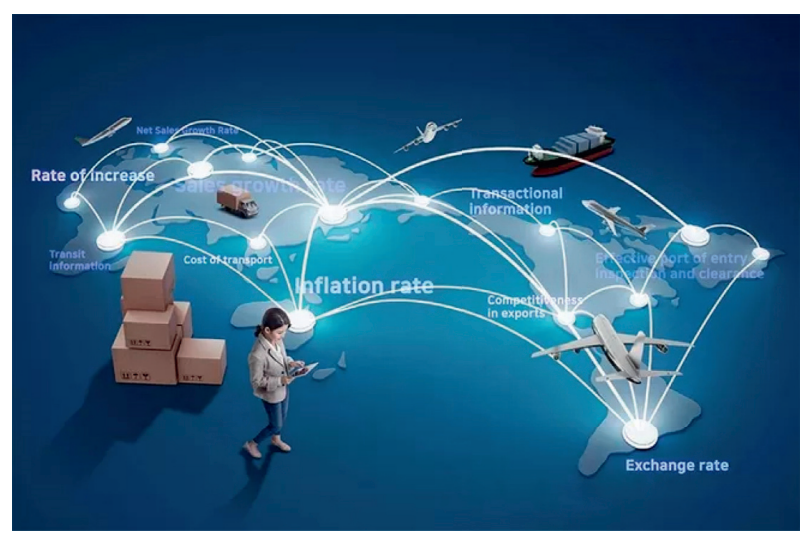

FIgure 1: Cross-border e-commerce.

province, this study selects the total in and out of foreigninvested enterprises, foreign direct investment, the number of patent applications, the total fixed assets, and the GDP of each province as the economic growth indicator variables.

\section{Cross-Border E-Commerce Development Impact Factor Model}

The development of cross-border e-commerce is a systematic project, which is affected by the environment and is closely related to the support of the domestic policy system and the international market environment. Domestically, the home country's market system environment, economic development level, national support policies, market maturity, and cultural values all have a certain potential or direct impact on the promotion of corporate brand internationalization, and the laws of the country where the product is imported policies, culture, and competitive environment also have a significant impact on the development of corporate brand internationalization. Enterprise development, trade policies, and cross-border trade facilitation, regional integration, promotion of foreign direct investment, enterprise clusters, and national innovation systems can help promote the participation of enterprises in global value chains.

The statistical idea of gray correlation analysis is to use the geometric similarity of the two-factor data sequence curve to represent the closeness of the relationship between the two factors. The higher the geometric similarity of the two-factor data sequence curve, the greater their correlation. The cross-border e-commerce ecosystem is shown in Figure 3.

The development of cross-border e-commerce requires necessary regulation, support, and training. Xu Mingxia and others believe that the factors that determine the development of trade include not only the hardware environment such as geographic location, natural resources, transportation routes, and infrastructure, but also the software environment such as market maturity, industrial development, institutional advantages, and policy dividends. Zhou Fang believes that industrial input and output, technological innovation, technological environment, 


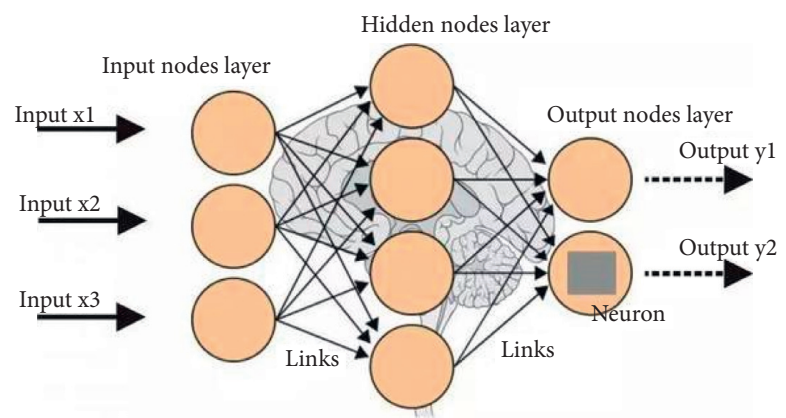

Figure 2: Neural networks.

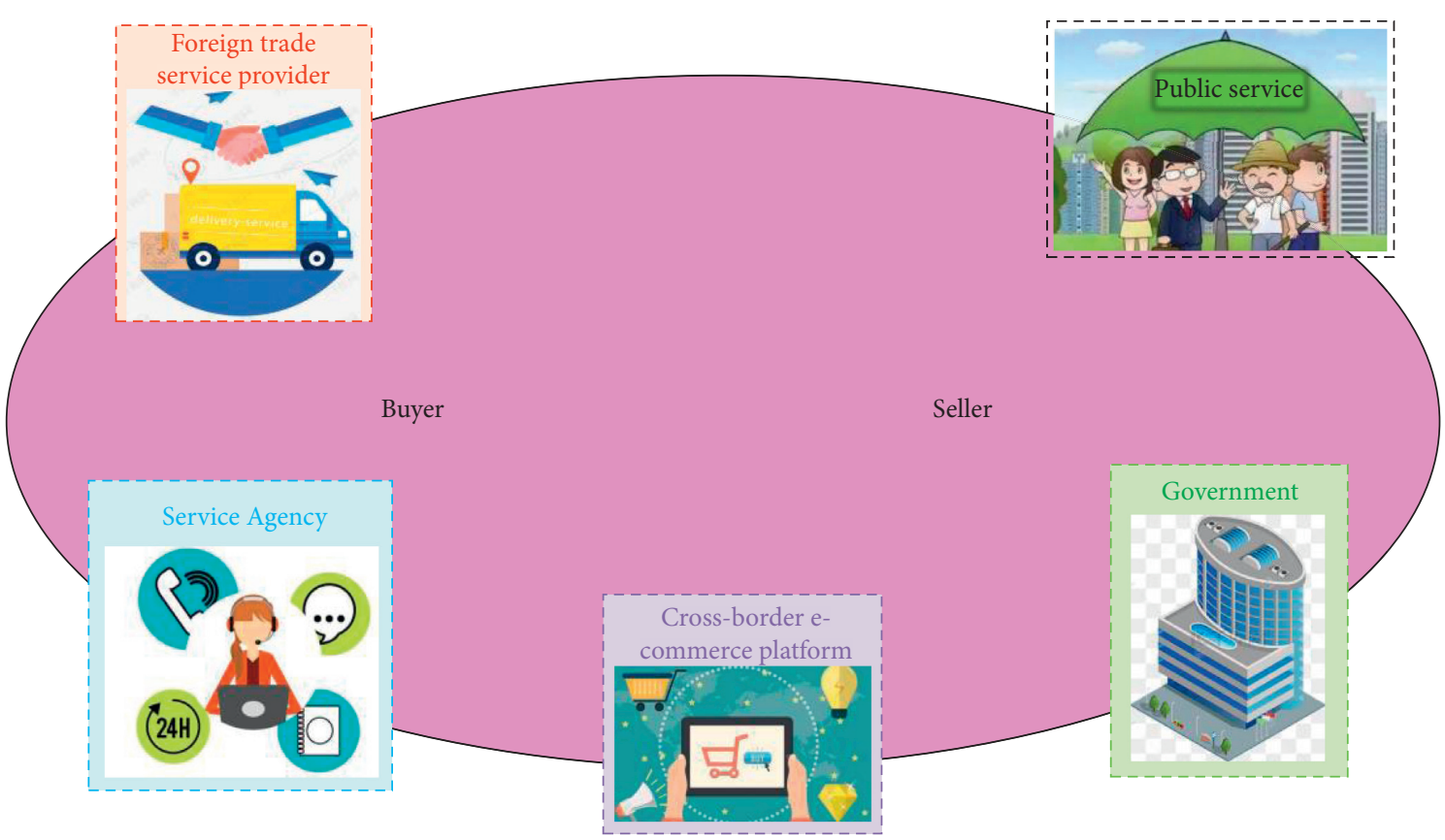

Figure 3: Cross-border e-commerce ecosystem.

development policies, support, and incubation have a greater impact. Xu Jinbo has constructed a cross-border e-commerce development evaluation system that includes five dimensions: network marketing, international logistics, electronic payment, electronic customs clearance, and government policies. Yang Jianzheng and others believe that online marketing, international payments, crossborder e-commerce logistics, cargo clearance, legal protection, and so on will have a huge impact on cross-border e-commerce.

Hao Binkai summarized the four major factors, including production factors, demand conditions, and corporate behavior. Chen Nan conducted research based on the perspective of complex networks and found that government support policies can increase the enthusiasm of enterprises to participate in cross-border e-commerce, but it will show short-term characteristics. Brand managers should focus on making products traceable, empower consumers, and strengthen coordination with local authorities to control counterfeiting. Zhang Xiaodong took e-commerce logistics, economic development, social consumption, talent environment, and technological innovation. The degree of coupling and coordination of the system.

Cross-border e-commerce is a complex industry that drives a wide range of industries, involves many industries, and has many regions and countries. It is related to all levels of economic development. First, the most important influence system for the development of cross-border e-commerce is the foundation of e-commerce, including trade, e-commerce platforms, and logistics and distribution; among them, the trade dimension includes trade basic factors and trade radiation factors, and the e-commerce dimension includes e-commerce development factors, e-commerce scale factor and e-commerce penetration factor. The logistics dimension includes logistics income factor and logistics business volume factor. Second, the development of export cross-border e-commerce needs the support of the local industrial economy. A large number of cross-border e-commerce industries can only provide products suitable 
for the international market and can highlight the scale effect and improve industrial efficiency; economic dimensions include economic scale factors and economic structure factor. The third is consumption power, which is directly related to the development of imported cross-border e-commerce. Only with certain consumption power can consumers have the economic basis for choosing and consuming high-quality products from all over the world; consumption dimensions include consumption income factors and consumption expenditures factor. The fourth is the driving force for the sustainable development of crossborder e-commerce, including talents and innovation. These two factors are ultimately the core competitiveness of crossborder e-commerce to enter the international market; the talent dimension includes talent training factors and talent attraction factors. The innovation dimension includes innovation input factor, input intensity factor, and input effect factor. The constructed cross-border e-commerce development impact factor model is shown in Figure 4. Combining existing research and the specific development of China's cross-border e-commerce industry, construct a cross-border e-commerce development impact factor analysis model.

\section{Example Analysis}

In the analysis model, the 100 million yuan is chosen as a measurement indicator. The trade basis chooses the city's total import and export (100 million yuan) as the measurement index; the indicator of trade radiation is that the pilot zone drives the province's total import and export (100 million yuan). For e-commerce development, use urban e-commerce development index; e-commerce scale use urban e-commerce scale index; e-commerce penetration use urban e-commerce penetration index. The logistics income uses the city express total revenue (100 million yuan) index; the logistics business volume uses the city express business volume (100 million pieces) index. The economic scale is measured by the city's GDP (100 million yuan); the economic structure is measured by the city's tertiary industry's share of GDP (\%). The number of undergraduates and graduate students $(10,000)$ in the experimental area is selected as the indicator for talent training; the urban talent attraction index is selected as the indicator for talent attraction. The indicator of innovation investment is the total $\mathrm{R} \& \mathrm{D}$ investment of the corresponding province (100 million yuan); the indicator of investment intensity is the $\mathrm{R} \& \mathrm{D}$ investment intensity of the corresponding province (\%). The predicted results based on MATLAB are shown in Figure 5, and the other results are compared in Figure 6.

Based on the gray correlation analysis model, the calculated absolute correlation, relative correlation, and comprehensive correlation. Sorted by absolute gray correlation, the top four are innovation input, logistics revenue, economic scale, and e-commerce scale, indicating that these four factors are closely related to the absolute increase in cross-border e-commerce transaction volume. According to the gray relative degree, the top four are the talent attraction of logistics business volume, logistics income, and e-commerce scale, indicating that these four factors match the absolute growth rate of cross-border e-commerce transaction volume. From a comprehensive perspective, logistics revenue, innovation investment, logistics business volume, e-commerce scale, and cross-border e-commerce development are the closest, as shown in Figure 7.

The number of year-end mobile phones X2, the number of domain names X3, the number of URLs X4, the number of Webpages $\mathrm{X} 5$, the mobile phone penetration rate $\mathrm{X} 6$, the Internet penetration rate $\mathrm{X} 7$, and the telephone penetration rate X8. The economic growth indicators are foreign direct investment $\mathrm{Y} 1$, the number of patent applications $\mathrm{Y} 2$, the total fixed assets Y3, the total entry and exit of foreign-invested enterprises Y4, and GDP Y5. Empirical analysis has been done.

According to the aforementioned analysis steps of the gray correlation model, the gray correlation degree between the Internet development level and economic growth indicators is calculated. According to the calculation results, it can be seen that (1) from the perspective of the development level of the Internet, the correlation between the number of Internet users (X1) and economic growth indicators in descending order is GDP (Y5) 0.894, total fixed assets (Y3) 0.823 , the number of patent applications (Y2) 0.777 , foreign direct investment (Y1) 0.728, and total foreign investment enterprises (Y4) 0.726. Similarly, the correlation between $\mathrm{X} 2 \sim \mathrm{X} 8$ and economic growth indicators can be obtained. Among them, the number of mobile phones at the end of the year (X2), the number of domain names (X3), the number of URLs (X4), the number of Webpages (X5), the mobile phone penetration rate (X6), the Internet penetration rate (X7), and the telephone penetration rate (X8) are important to the economy. The maximum correlation degree of the growth indicators corresponds to GDP (Y5) 0.887, the number of patent applications (Y2) 0.855 , foreign direct investment (Y1) 0.865 , foreign direct investment (Y1) 0.880, and total fixed assets (Y3) 0.618, the number of patent applications (Y2) 0.687 , and the total in and out of foreign-invested enterprises (Y4) 0.760 . The average correlation between the number of Internet users (X1), the number of domain names (X3), and the number of URLs (X4), and the five economic growth indicators are $0.790,0.792$, and 0.794 , respectively, which is a relatively high correlation among the eight indicators. For the three notable ones, it can be considered that the Internet infrastructure and popularity have the closest relationship with economic growth. The weights are compared in Figure 8.

(2) From the perspective of economic growth, the correlation between foreign direct investment (Y1) and the eight indicators of the Internet development level, in descending order, is the number of Webpages (X5) 0.880, the number of URLs (X4) 0.865 , and the number of domain names (X3) 0.843 , telephone penetration rate (X8) 0.759 , number of people online (X1) 0.728 , year-end number of mobile phones (X2) 0.725, Internet penetration rate (X7) 0.680, and mobile phone penetration rate (X6). Foreign direct investment has the largest correlation with the number of Webpages, and the smallest correlation with mobile phone penetration. The number of patent applications (Y2), total fixed assets (Y3), total import and export volume of foreign-invested enterprises (Y4), and GDP (Y5) correspond to the number of 


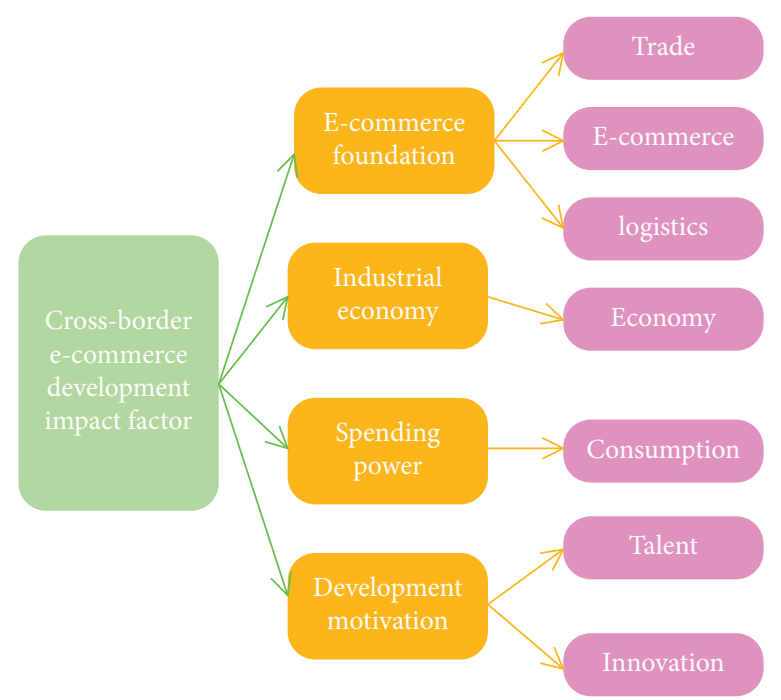

Figure 4: Cross-border e-commerce development impact factor model.
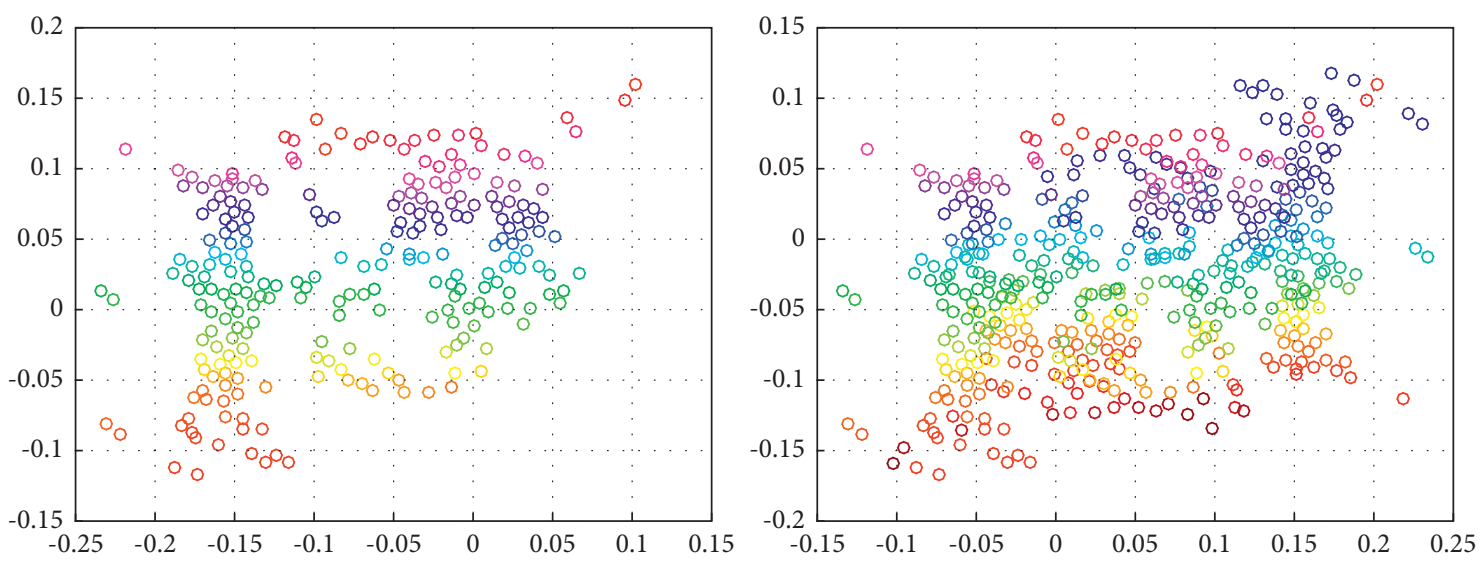

Figure 5: Predicted results.
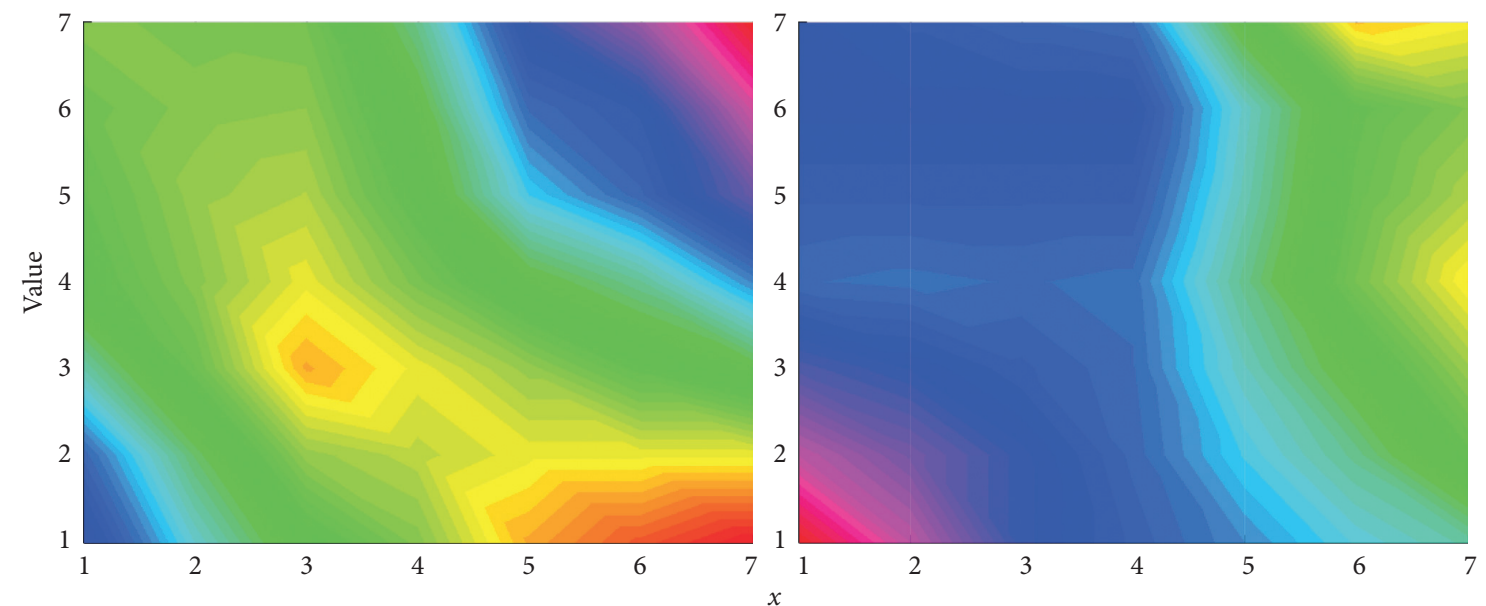

FIgURE 6: Result comparison. 

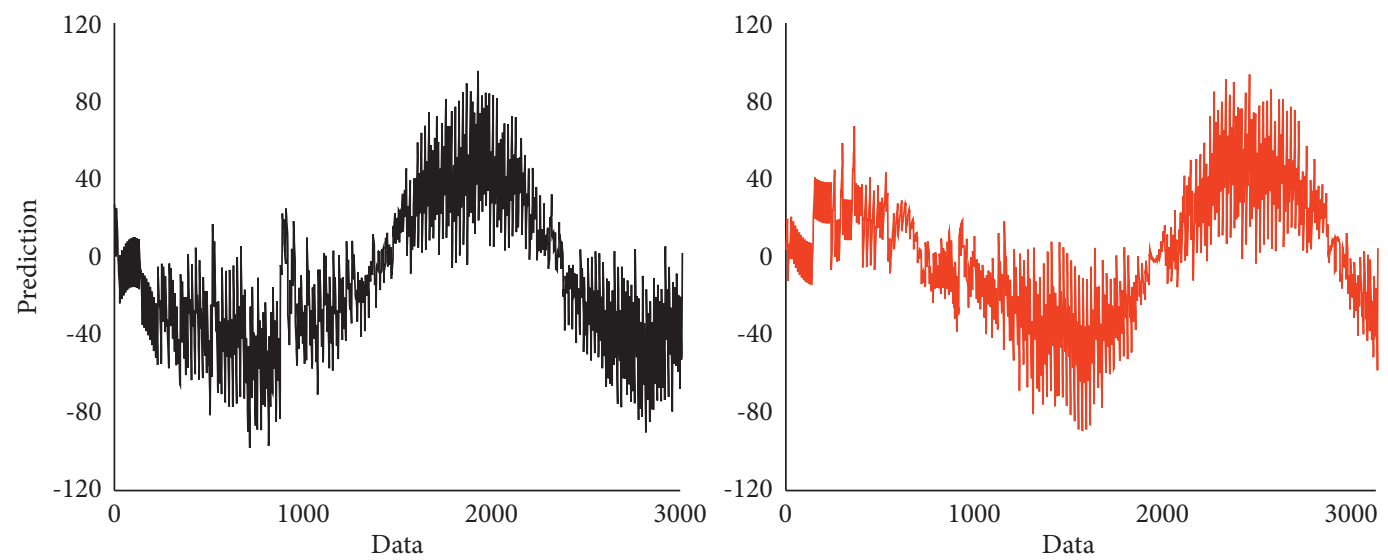

Figure 7: Prediction.
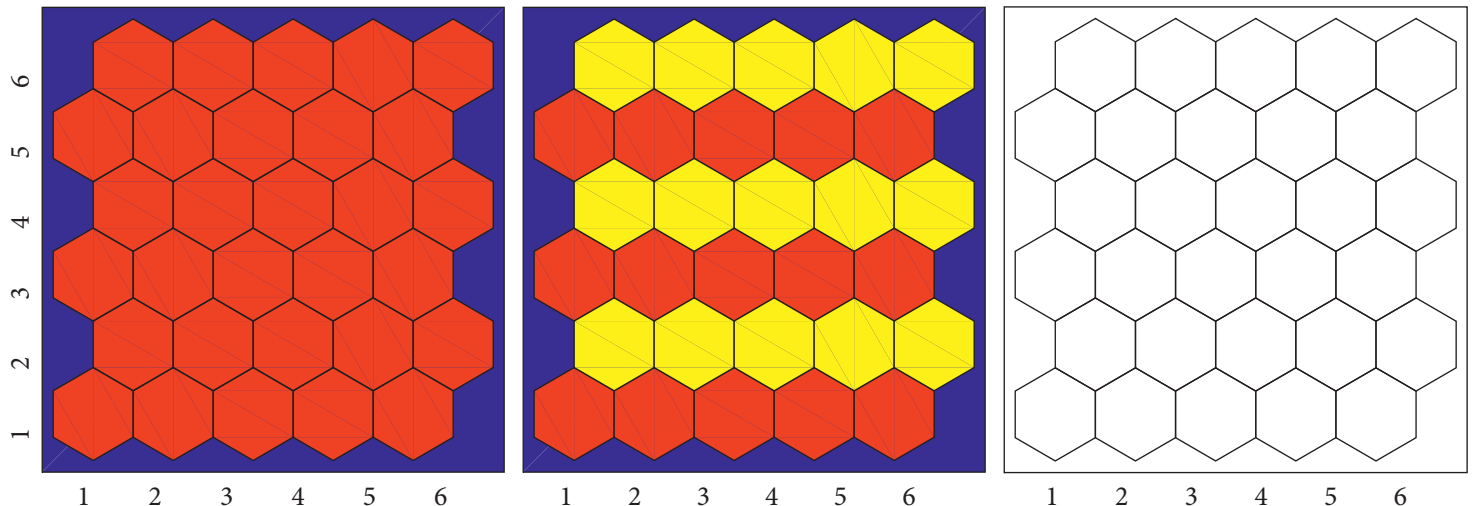

Figure 8: Weight comparison.

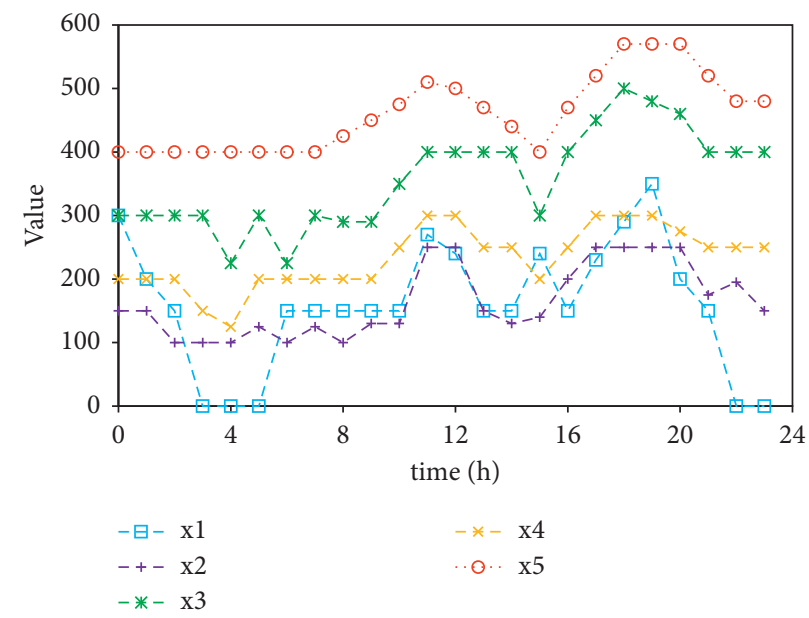

Figure 9: Value versus time.

domain names (X3) 0.855 and the number of Internet users (X1) 0.823 , the number of Webpages (X5) 0.879 , the number of people surfing the Internet (X1) 0.894, the minimum relevance index is the mobile phone penetration rate (X6), and the relevance values are $0.479,0.618$, and 0 , respectively.
From the two average correlation values being $0.743,0.745$, and 0.743 , it can be considered that foreign investment and patent applications have the closest relationship with the development level of the Internet. The value versus time is shown in Figures 9 and 10. 


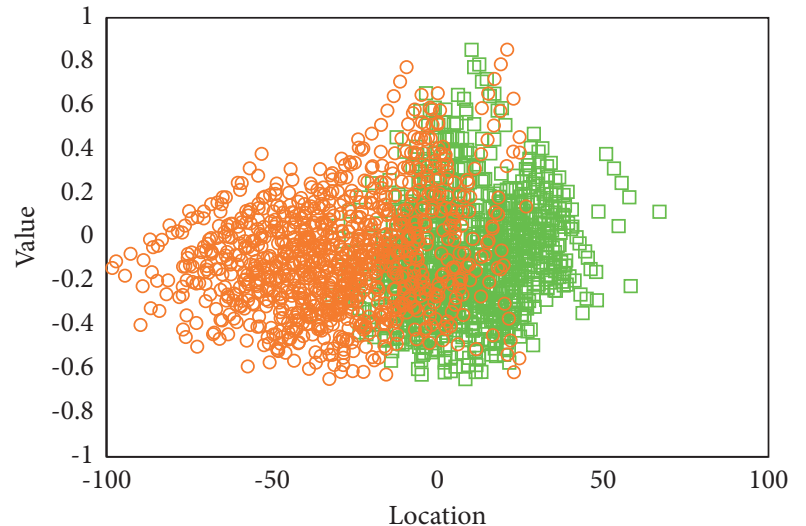

Figure 10: Value versus location.

\section{Conclusion}

Selecting the annual data of 31 provinces in China in 2015, empirical analysis of the degree of correlation between the level of Internet development and economic growth indicators. According to the empirical results, the following conclusions can be drawn: foreign direct investment has the greatest correlation with the number of websites and Webpages, and the smallest correlation with the penetration rate of mobile phones and the Internet.

(1) The number of patent applications has the largest correlation with the number of domain names and URLs, and the smallest correlation with the penetration rate of mobile phones and the Internet. The total fixed assets have the greatest correlation with the number of Internet users and the number of mobile phones at the end of the year, and the smallest correlation with the number of Webpages and the penetration rate of mobile phones.

(2) The total volume has the largest correlation with the number of websites and Webpages, and the smallest correlation with the penetration rate of mobile phones and the Internet. GDP has the largest correlation with the number of people surfing the Internet and the number of mobile phones at the end of the year, and the smallest correlation with the number of Webpages and the penetration rate of mobile phones.

(3) Internet infrastructure and popularity have the closest relationship with economic growth, and the relationship between foreign investment and patent applications and the level of Internet development is the most significant. Cross-border e-commerce supply chain greatly affects consumer experience and corporate core capabilities.

(4) A good supply chain can not only reduce operating costs but also deliver products as quickly as possible. Speed reaches the hands of consumers, so it is necessary to vigorously connect domestic and foreign logistics, unblock international logistics channels, and vigorously develop overseas warehouse business; second, enhance the R\&D and design innovation capabilities of cross-border e-commerce companies and conduct in-depth research and analysis of market environment and consumer habits, and so on.

\section{Data Availability}

The data used to support the findings of this study are available from the corresponding author upon request.

\section{Conflicts of Interest}

The authors declare that they have no known competing financial interests or personal relationships that could have appeared to influence the work reported in this paper.

\section{References}

[1] Y. Yu, C. Yang, Q. Deng, T. Nyima, S. Liang, and C. Zhou, "Memristive network-based genetic algorithm and its application to image edge detection," Journal of Systems Engineering and Electronics, vol. 32, no. 5, pp. 1-9, 2021.

[2] Y. Ishida and S. Hashimoto, "Asymmetric characterization of diversity in symmetric stable marriage problems: an example of agent evacuation," Procedia Computer Science, vol. 60, no. 1, pp. 1472-1481, 2015.

[3] P. Zoha and R. Kaushik, "Image edge detection based on swarm intelligence using memristive networks," IEEE Transcations on CAD of Integrated Circuits and Systems, vol. 37, no. 9, pp. 1774-1787, 2018.

[4] J. Pais, "Random matching in the college admissions problem," Economic Theory, vol. 35, no. 1, pp. 99-116, 2018.

[5] J. J. Jung and G. S. Jo, "Brokerage between buyer and seller agents using constraint satisfaction problem models," Decision Support Systems, vol. 28, no. 4, pp. 291-384, 2020.

[6] Y. Liu and K. W. Li, "A two-sided matching decision method for supply and demand of technological knowledge," Journal of Knowledge Management, vol. 21, no. 3, 2017.

[7] J. Byun and S. Jang, "Effective destination advertising: matching effect between advertising language and destination type," Tourism Management, vol. 50, no. 10, pp. 31-40, 2015.

[8] A. N. Nagamani, S. N. Anuktha, N. Nanditha, and V. K. Agrawal, "A genetic algorithm-based heuristic method for test set generation in reversible circuits," IEEE Transactions on Computer-Aided Design of Integrated Circuits and Systems, vol. 37, no. 2, pp. 324-336, 2018.

[9] C. Koch and S. P. Penczynski, “The winner's curse: conditional reasoning and belief formation," Journal of Economic Theory, vol. 174, pp. 57-102, 2018.

[10] C. K. Karl, "Investigating the winner's curse based on decision making in an auction environment," Simulation \& Gaming, vol. 47, no. 3, pp. 324-345, 2016.

[11] D. Ettinger and F. Michelucci, "Creating a winner's curse via jump bids," Review of Economic Design, vol. 20, no. 3, pp. 173-186, 2016.

[12] J. A. Brander and E. J. Egan, "The winner's curse in acquisitions of privately-held firms," The Quarterly Review of Economics and Finance, vol. 65, pp. 249-262, 2017.

[13] Z. Palmowski, "A note on var for the winner's curse," Economics, vol. 15, no. 3, pp. 124-134, 2017. 
[14] B. R. Routledge and S. E. Zin, "Model uncertainty and liquidity," Review of Economic Dynamics, vol. 12, no. 4, pp. 543-566, 2009.

[15] D. Easley and M. O'Hara, "Ambiguity and nonparticipation: the role of regulation," The Review of Financial Studies, vol. 22, no. 5, pp. 1817-1843, 2019.

[16] P. Klibano, M. Marinacci, and S. Mukerji, "A smooth model of decision making under ambiguity," Econometrica, vol. 73, no. 6, pp. 1849-1892, 2005.

[17] Y. Halevy, "Ellsberg revisited: an experimental study," Econometrica, vol. 75, no. 2, pp. 503-536, 2017.

[18] D. Ahn, S. Choi, D. Gale, and S. Kariv, "Estimating ambiguity aversion in a portfolio choice experiment," Quantitative Economics, vol. 5, no. 2, pp. 195-223, 2019.

[19] T. Hayashi and R. Wada, "Choice with imprecise information: an experimental approach," Theory and Decision, vol. 69, no. 3, pp. 355-373, 2010.

[20] K. Zima, E. Plebankiewicz, and D. Wieczorek, "A SWOT analysis of the use of BIM technology in the polish construction industry," Buildings, vol. 10, no. 1, 2020.

[21] P. Sun, B. Liu, and T. Sun, "Injury status and strategies of female 7 -a-side rugby players in Anhui Province," Sports Boutique, vol. 38, no. 03, pp. 72-74, 2019.

[22] P. Guild, M. R. Lininger, and M. Warren, "The association between the single leg hop test and lower-extremity injuries in female athletes: a critically appraised topic," Journal of Sport Rehabilitation, vol. 30, no. 2, pp. 1-7, 2020.

[23] U. G. Inyang, E. E. Akpan, and O. C. Akinyokun, "A hybrid machine learning approach for flood risk assessment and classification," International Journal of Computational Intelligence and Applications, vol. 19, no. 2, Article ID 2050012, 2020.

[24] Q. Liu, S. Du, B. Wyk, and Y. Sun, "Double-layer-clustering differential evolution multimodal optimization by speciation and self-adaptive strategies," Information Sciences, vol. 545, no. 1, pp. 465-486, 2021.

[25] H. R. Medeiros, F. D. Oliveira, H. F. Bassani, and A. Araujo, "Dynamic topology and relevance learning SOM-based algorithm for image clustering tasks," Computer Vision and Image Understanding, vol. 179, pp. 19-30, 2019.

[26] Y. Deng, D. Huang, S. Du, G. Li, and J. Lv, "A double-layer attention based adversarial network for partial transfer learning in machinery fault diagnosis," Computers in Industry, vol. 127, Article ID 103399, 2021.

[27] J. J. Chan, K. K. Chen, and S. Sarker, "Epidemiology of Achilles tendon injuries in collegiate level athletes in the United States," International Orthopaedics, vol. 44, no. 3, pp. 585-594, 2020.

[28] W. Li, G. G. Wang, and A. H. Gandomi, "A survey of learningbased intelligent optimization algorithms," Archives of Computational Methods in Engineering, vol. 28, pp. 1-19, 2021.

[29] G. G. Wang, A. H. Gandomi, A. H. Alavi, and D. Gong, “A comprehensive review of krill herd algorithm: variants, hybrids and applications," Artificial Intelligence Review, vol. 51, no. 1, pp. 119-148, 2019. 